\title{
From hydrological modelling to decision support
}

\author{
U. Haberlandt \\ Institute of Water Resources Management, Hydrology and Agricultural Hydraulic Engineering, \\ Leibniz University of Hannover, Hannover, Germany
}

Received: 1 February 2010 - Revised: 20 May 2010 - Accepted: 30 May 2010 - Published: 23 August 2010

\begin{abstract}
Decision support for planning and management of water resources needs to consider many target criteria simultaneously like water availability, water quality, flood protection, agriculture, ecology, etc. Hydrologic models provide information about the water balance components and are fundamental for the simulation of ecological processes. Objective of this contribution is to discuss the suitability of classical hydrologic models on one hand and of complex ecohydrologic models on the other hand to be used as part of decision support systems. The discussion is based on results from two model comparison studies. It becomes clear that none of the hydrologic models tested fulfils all requirements in an optimal sense. Regarding the simulation of water quality parameters like nitrogen leaching a high uncertainty needs to be considered. Recommended for decision support is a hybrid metamodel approach, which comprises a hydrologic model, empirical relationships for the less dynamic processes and makes use of simulation results from complex eco-hydrologic models through second-order modelling at a generalized level.
\end{abstract}

\section{Introduction}

Integrated water resources management requires modelling of various hydrological and ecohydrological processes like infiltration, runoff generation, groundwater recharge, evapotranspiration, vegetation and crop growth, nitrate and phosphorous dynamics, erosion, sewage system dynamics, water regulations, etc. A joint modelling of all these processes leads to complex modelling systems (Arnold and Fohrer, 2005; Krysanova et al., 1998), which are very demanding regarding data and can be operated often only by especially trained experts.

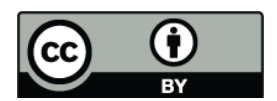

Correspondence to: U. Haberlandt (haberlandt@iww.uni-hannover.de)
Another way is to use simple empirical approaches (Berlekamp et al., 2007; Johnes, 1996; Kunkel and Wendland, 2002), which aim at providing the target variables at the policy scale in the form of long term averages. These approaches are easy to be applied within a GIS framework or in decision support systems. However, they often include observed streamflow and don't consider the nonlinear and dynamic character of water and nutrient processes and therefore may fail for unobserved basins or in the prognosis of changes.

A recent alternative is to use some kind of hybrid and/or metamodelling framework, where the major processes are modelled with tailor-made concepts depending on process complexity, available data and modelling purpose (Haberlandt et al., 2001; Quinn et al., 2008; Shrestha et al., 2007). The diverse modules may be based on conceptual, empirical or artificial intelligence approaches and can be operated at various time steps with different levels of complexity. A metamodel utilises simplified but dynamic models as surrogate for physically based process models. These metamodels are especially suitable for the efficient simulation of complex processes like nitrogen dynamics within decision support systems.

Still, this leaves the question of how to simulate the dynamic water fluxes which drive such ecohydrological processes. For that classical hydrological models might be used. Today there are numerous hydrological models available for calculating water balance components at different spatial and temporal scales. So, a selection of one suitable hydrological model, which serves as a module in a more complex decision support system for integrated water resources management, should be possible.

In this paper the following three questions are addressed:

1. Are the classical hydrologic models suitable to be used as part of decision support systems?

Published by Copernicus Publications on behalf of the European Geosciences Union. 
Table 1. Requirements on hydrological models to be used as part of decision support systems.

\begin{tabular}{lll}
\hline No. & Criterion & Requirements \\
\hline 1 & Spatial scale & Highly distributed approach required \\
2 & Temporal scale & Daily time step with continuous long term applicability \\
3 & Degree of determination & Conceptual approach with prognostic capabilities; use of parameters \\
& & which are related to physical catchment properties \\
4 & Target variables & Infiltration, percolation, evapotranspiration, at least three runoff components, river discharge \\
5 & Complexity, handling & Moderate complexity with modest number of parameters; robust approach; easy handling \\
6 & Efficiency & Fast computing required \\
7 & Performance & Sufficient performance on monthly time step, small bias for long term behaviour \\
8 & Sensitivity & Climate, soils, land use, agricultural management e.g. crop rotations \\
\hline
\end{tabular}

2. What is the suitability of complex eco-hydrologic models to be operated in the framework of decision support systems?

3. What are appropriate alternatives for using process models for applications in DSS?

The paper is organised as follows. After this introduction two model comparison studies are presented. In the Sect. 2 the three hydrologic models HEC-HMS, WASIM-ETH and SWAT are evaluated regarding several test criteria. In Sect. 3 the eco-hydrologic models SWIM, CANDY and HERMES are compared considering their ability to simulate percolation and nitrogen leaching and a possible integration of model results is discussed. Section 4 deals with an alternative concept to using process models in DSS and in Sect. 5 conclusions are drawn.

\section{Model comparison - hydrology}

\subsection{Requirements on hydrological models}

This first example summarizes results from a model comparison study presented in greater detail in Haberlandt et al. (2009). Table 1 contains a not complete list of requirements for hydrological models, which are to be used as part of decision support systems or within a metamodel framework. The simulation of hydrological fluxes is required on a high spatial resolution, possibly on a raster, in order to allow the identification of critical areas or to analyse local scenarios for change. Although usually only long term behaviour, possibly with seasonal discretisation is required for policy decisions, the hydrological model should run on a daily time step. This takes into account the non-linear processes like runoff generation, considers the best available information density regarding climate data and allows choosing from a large number of well established modelling approaches. Suitable model types are the modern conceptual approaches relying on a modest number of parameters which are related to basin properties and have sufficient prognostic capabilities. The model should be able to simulate separately all terrestrial based water balance components e.g. percolation, transpiration, etc. and to consider the different runoff pathways in order to provide the specific relevant fluxes for the water quality modules. The selected approach should be of moderate complexity in order to allow a robust application of the model by water managers and fast computations. A good model performance is required on a monthly scale with an appropriate seasonal reproduction and a small bias regarding long term results. Most important is, that the model is sensitive to land use and management changes e.g. regarding crop rotations.

\subsection{Hydrological models and data}

The three different well established hydrological models HEC-HMS, WaSIM-ETH and SWAT are tested here regarding a possible application within a decision support system.

HEC-HMS (Fleming and Neary, 2004) is a classical conceptual semi-distributed rainfall-runoff model. It uses the soil moisture accounting (SMA) algorithm for runoff generation, the Clark Unit Hydrograph for the transformation of direct runoff, two linear reservoirs to consider interflow and base flow transformation and the kinematic wave for river routing. Snow melt is calculated externally using the degree day method. Potential evapotranspiration is estimated using the Priestley-Taylor method. Here, HEC-HMS version 3.1 is used.

The model WaSiM-ETH (Schulla, 1997) is a more complex process-based fully distributed hydrological model for the simulation of hydrological fluxes on a rectangular grid. Besides the digital elevation model input data grids for soil properties and land use are required. Soil water balance and runoff generation is modelled using a modified variable saturated area approach (top-model). The kinematic wave is used in combination with a single linear storage for discharge routing. Evapotranspiration is calculated after Penman-Monteith and snow melt using a temperatureindex-approach. Here WaSiM-ETH version 7.9.11 is used. It should be noted that WaSiM-ETH offers alternatively the 


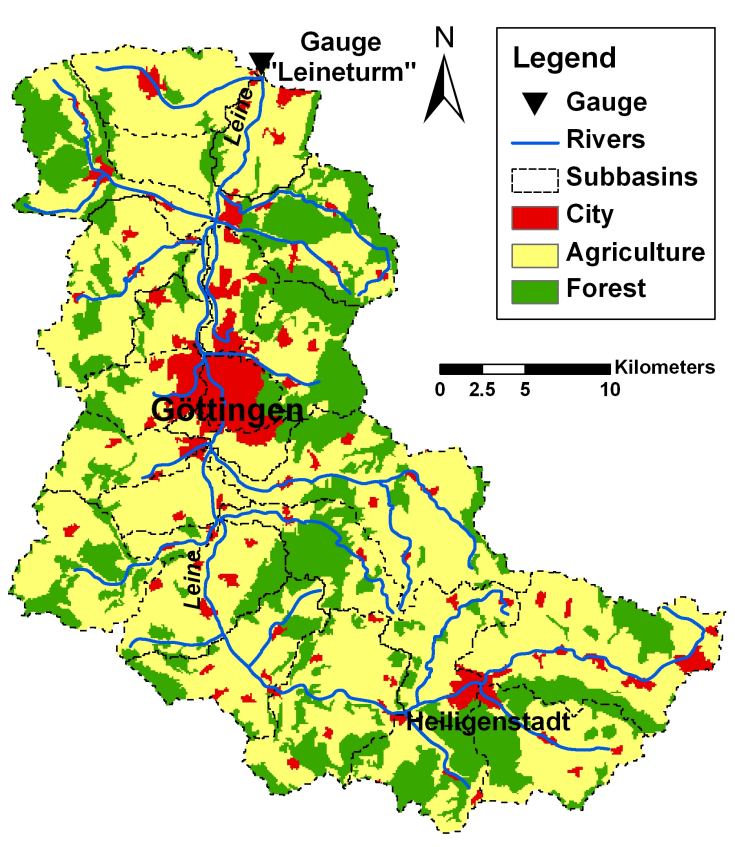

Fig. 1. Overview of the upper Leine catchment with major land use and river network.

Richards equation approach for soil water dynamics and a recent version also includes crop rotations, which could not be applied here.

The third model SWAT (Arnold and Fohrer, 2005) is a semi-distributed model capable to simulate runoff, nutrients and other agricultural chemicals as well as sediment yield in large complex watersheds with varying soils, land use, and management conditions. Evapotranspiration is calculated here after Penman-Monteith, snow melt with the degree day method, infiltration based on the SCS curve number method, runoff transformation using a surface runoff lag method and flood routing is calculated with the variable storage method. Here, SWAT version 2005 is used.

The investigations are carried out for the upper Leine river basin in northern Germany with a drainage area of about $1000 \mathrm{~km}^{2}$. This region represents quite a diversity of physiographic and climatic characteristics with elevations from 115 to $533 \mathrm{~m}$ a.s.l. and mean annual precipitation between 570 and $860 \mathrm{~mm} / \mathrm{yr}$. Figure 1 gives an overview of the study area with rough land use characteristics, river network und subbasin delineation. $62 \%$ of the river basin area is agricultural land, which is significant for the assessment of diffuse pollution depending on management practice. Available physiographic data were compiled from a $90 \mathrm{~m}$ digital elevation model, land use from CORINE and soil information from the BUEK1000 (Hartwich et al., 1995). Precipitation data result from about 50 daily rainfall gauges and other climate data from about 10 climate stations. Climate data are interpolated on a $450 \mathrm{~m}$ rectangular grid for use with WaSIM-ETH and then aggregated to subcatchment averages for use with the other two models.

\subsection{Model comparison}

The three models are compared using the criteria defined in Table 1. The results are summarised in Table 2.

All models are operated continuously on a daily time step with a detailed raster discretisation for WaSIM and a moderate subbasin delination for HEC-HMS and SWAT. The WaSIM and SWAT models are of higher complexity compared to HEC especially because of the raster discretisation in WaSIM and the consideration of crop dynamics in SWAT. All models are able to generate the required target variables.

The number of parameter differs significantly between the models. Parameters are counted here for each simulation unit separately considering hydrotop classes and subbasins. SWAT needs the largest number of parameters in total because of the detailed consideration of the ecohydrologic processes like crop growth and nitrogen dynamics. Also WaSIM-ETH needs many parameters taking into account the raster discretisation. HEC-HMS requires less parameter in total, but the largest number is considered for calibration (4 parameters times 25 subbasins). Usually the degrees of freedoms increase with increasing number of parameters and the robustness of the model decreases.

The three hydrological models have been calibrated using the observation period from November 1980 to October 1996 and validated for the period from November 1996 to October 2005 using discharge data for the outlet gauge Leineturm (see Fig. 1). So, the total simulation period comprises 25 years. The fastest running model for this period is HEC-HMS, followed by WaSIM-ETH and the SWAT, but the absolute differences are small. Calibration takes longest for HEC-HMS. The performance for discharge simulation at the outlet gauge is of similar quality for all three models (see Table 2 and Fig. 2).

An important part of the model comparison concerns the sensitivity for change. Five different scenarios have been investigated. In the deforestation scenario the agricultural area has been increased by $15 \%$ at the expense of forested area. For urbanisation the urban area has been increased by $26 \%$ at the expense of agricultural land. In the afforestation scenario the forested areas have been increased by $30 \%$ at the expense of agricultural land. In the crop rotation scenario the three crop rotations considered in SWAT for the Leine catchment have been replaced by wheat as one single crop for all agricultural areas. In the fertilisation scenario a decrease of the total nitrogen application by $25 \%$ is simulated. HEC-HMS shows only very small responses to all of these scenarios. WaSIM-ETH shows a considerable reaction for the deforestation and afforestation scenarios. Surprisingly SWAT does not show significant reactions to the land use change scenarios. This might be attributed to the seasonal variation of both crops and natural vegetation in SWAT, driven mainly by the leaf area index. However, the crop rotation scenario shows a moderate response from SWAT, while the fertilisation scenario shows no sensitivity in the water balance. The crop 

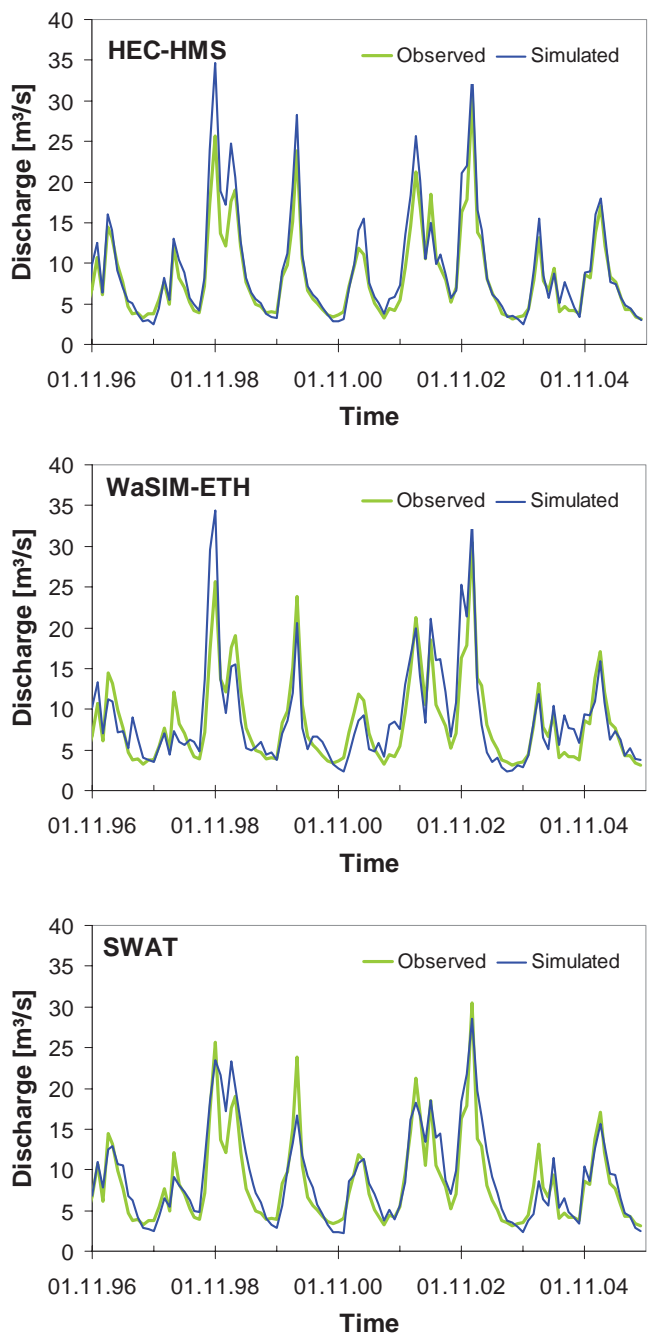

Fig. 2. Observed and simulated monthly discharge time series using the three different models for the validation period at the outlet gauge Leineturm.

rotation and fertilisation scenarios cannot be simulated by HEC-HMS and WaSIM-ETH, which shows a problem for conceptual hydrological models, which usually cannot account for agricultural management. In general it should be born in mind, however, that an absolute evaluation of the change scenarios is impossible since no such changes are observed.

\section{Model comparison - eco-hydrology}

\subsection{Eco-hydrological models and data}

The second example reviews results from a model comparison study, where three different ecohydrological models: SWIM (Krysanova et al., 1998), CANDY (Franko et al., 1995) and HERMES (Kersebaum, 1995) are compared (Haberlandt et al., 2002). The models are applied for long-term simulation of water and nutrient fluxes in the

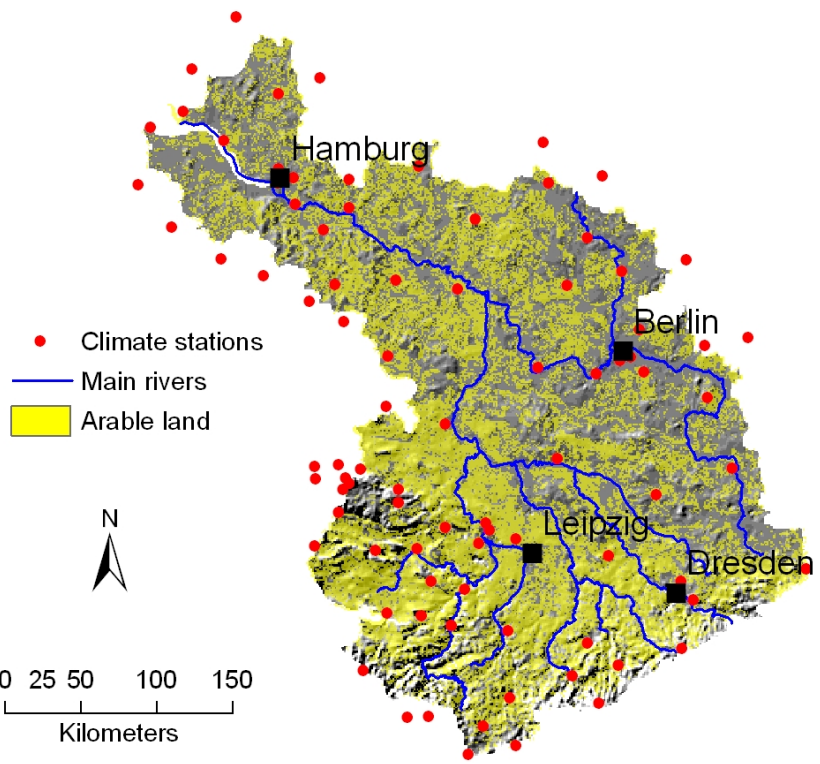

Fig. 3. German part of the Elbe River Basin with climate stations and arable land areas indicated by transparent yellow colour on top of shaded relief.

$96400 \mathrm{~km}^{2}$ German part of the Elbe River basin (Fig. 3). Simulation experiments were planned according to the variations in natural and management conditions for agricultural areas (49\% from total area) in the Elbe River Basin. Four main factors were considered: soils, climate, crop rotations and fertilization (see Table 3).

Soils occurring on arable land from a small scale soil map (1:1 000000 , BÜK 1000), (Hartwich et al., 1995) were classified into nine classes taking into account field capacity and saturated hydraulic conductivity. For the definition of management options the nine soil classes were grouped into three soil quality groups: "good soils", "intermediate soils" and "poor soils" according to their potential for crop yield (Scheffer and Schachtschabel, 1984). Six climate stations were selected based on a simple cluster analysis using the two variables long term average annual temperature and precipitation. Also considered were completeness regarding observed variables and missing records as well as geographical location. For the application of the three models the following climate variables are required: precipitation, mean, minimum and maximum temperature, humidity, hours of bright sunshine and global radiation. One characteristic crop rotation with a length of six years including a basic fertilization scheme was associated to each of the soil quality groups according to the typical management practice in the region. In addition one simple intensification and extensification option for fertilization was considered. Altogether a set of 162 different variants $(9$ soils/management schemes times 6 climate regions times 3 fertilization options) was simulated by the three models over a period of 30 years on a daily time step. 
Table 2. Results for the comparison of the models HEC-HMS, WaSIM-ETH and SWAT.

\begin{tabular}{|c|c|c|c|c|c|}
\hline No. & Criterion & Sub-Criteria & HEC-HMS & WaSIM-ETH & SWAT \\
\hline 1 & Spatial scale & $\begin{array}{l}\text { No. subbasins: } \\
\text { Hydrotope classes: }\end{array}$ & $\begin{array}{c}25 \\
4\end{array}$ & $\begin{array}{c}25 \\
4889 \text { grids }\end{array}$ & $\begin{array}{l}25 \\
\sim 25\end{array}$ \\
\hline 2 & Temporal scale & & day & day & day \\
\hline 3 & Degree of determination & & medium & medium/high & medium/high \\
\hline 4 & Target variables & & $Q$, ET, PERC, RO, RI, RB & $Q, \mathrm{ET}, \mathrm{PERC}, \mathrm{RO}, \mathrm{RI}, \mathrm{RB}$ & $Q, \mathrm{ET}, \mathrm{PERC}, \mathrm{RO}, \mathrm{RI}, \mathrm{RB}$ \\
\hline 5 & $\begin{array}{l}\text { Complexity, } \\
\text { parameters, } \\
\text { handling }\end{array}$ & $\begin{array}{l}\text { Total parameters: } \\
\text { Calibration param.: } \\
\text { Handling: }\end{array}$ & $\begin{array}{c}\sim 350 \\
100 \\
\text { easy }\end{array}$ & $\begin{array}{c}\sim 500 \\
9 \\
\text { moderate }\end{array}$ & $\begin{array}{c}\sim 3000^{(5)} \\
12 \\
\text { difficult }\end{array}$ \\
\hline 6 & Efficiency & $\begin{array}{c}\text { Runtime: } \\
\text { Calibration time: }\end{array}$ & $\begin{array}{c}2 \min \\
84 \mathrm{~h}^{(3)}\end{array}$ & $\begin{array}{l}4 \min \\
8 h^{(3)}\end{array}$ & $\begin{array}{l}5 \min \\
-(4)\end{array}$ \\
\hline 7 & $\begin{array}{l}\text { Performance } \\
\text { calib./valid. }\end{array}$ & $\begin{array}{c}\text { Bias [\%]: } \\
\text { Nash-Sutcliffe: }\end{array}$ & $\begin{array}{c}9 / 13 \\
0.84 / 0.84\end{array}$ & $\begin{array}{c}-7 / 4 \\
0.83 / 0.70\end{array}$ & $\begin{array}{c}-2 / 8 \\
0.84 / 0.82\end{array}$ \\
\hline 8 & Sensitivity for change ${ }^{(2)}[\%]$ & $\begin{array}{l}\text { Deforestation: } \\
\text { Urbanisation: } \\
\text { Afforestation: } \\
\text { Crop rotation: } \\
\text { Fertilisation: }\end{array}$ & $\begin{array}{l}+1.6 \\
+2.0 \\
-1.3 \\
\text { none } \\
\text { none }\end{array}$ & $\begin{array}{c}+11.3 \\
-0.9 \\
-10.2 \\
\text { none } \\
\text { none }\end{array}$ & $\begin{array}{c}+0.2 \\
-0.6 \\
-0.6 \\
+3.4 \\
0.0\end{array}$ \\
\hline
\end{tabular}

$Q$ - river discharge, ET - evapotranspiration, PERC - percolation; RO - surface runoff, RI - interflow, RB - base flow; (1): monthly performance; (2): percent change of total Q for scenario relative to actual status; (3) using automatic calibration; (4) manual calibration; (5) without plant specific parameters and crop rotation characteristics.

Table 3. Overview of the simulation variants.

\begin{tabular}{|c|c|}
\hline Factor & Classification \\
\hline Soil classes & 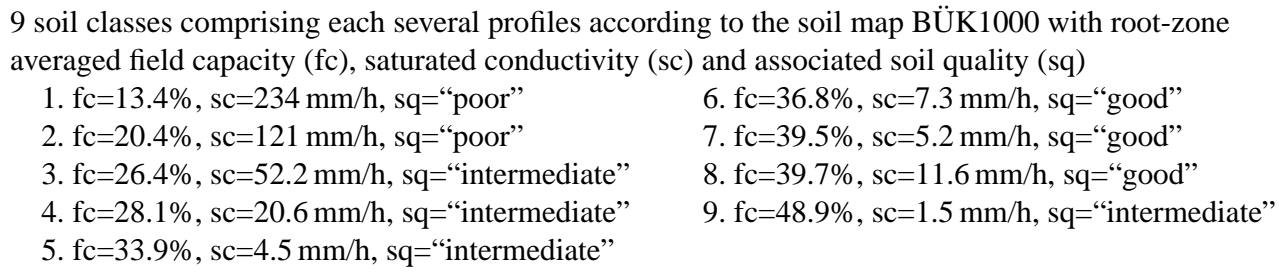 \\
\hline Climate regions & $\begin{array}{l}6 \text { climate regions according to average } P \text { and } T \text { (period 1961-1990) } \\
\text { 1. Magdeburg-West (ID3177), } P=494 \mathrm{~mm} / \mathrm{yr}, T=8.8^{\circ} \mathrm{C} \\
\text { 2. Potsdam (ID3342), } P=588 \mathrm{~mm} / \mathrm{yr}, T=8.8^{\circ} \mathrm{C} \\
\text { 3. Gera Leumnitz (ID4406), } P=615 \mathrm{~mm} / \mathrm{yr}, T=7.9^{\circ} \mathrm{C} \\
\text { 4. Dresden Klotzsche (ID3386), } P=652 \mathrm{~mm} / \mathrm{yr}, T=9.0^{\circ} \mathrm{C} \\
\text { 5. Hof Hohensaas (ID4027), } P=742 \mathrm{~mm} / \mathrm{yr}, T=6.4^{\circ} \mathrm{C} \\
\text { 6. Hamburg Fuhls. (ID1459), } P=770 \mathrm{~mm} / \mathrm{yr}, T=8.7^{\circ} \mathrm{C}\end{array}$ \\
\hline Management schemes & $\begin{array}{l}3 \text { crop rotations + basic fertilization } \\
\text { 1. good soils: sbe, ww, wb, wra, ww, wb; fertilization: } 168 \mathrm{~kg} \mathrm{Nha}^{-1} \mathrm{yr}^{-1} \\
\text { 2. average soils: sm, ww, wb, wra, ww, sb } \mathrm{se}^{* 1} \text {, fertilization: } 143 \mathrm{~kg} \mathrm{Nha}^{-1} \mathrm{yr}^{-1} \\
\text { 3. poor soils: pot, wb, wr, sm*1, wr, sb*1, fertilization: } 122 \mathrm{~kg} \mathrm{Nha}^{-1} \mathrm{yr}^{-1}\end{array}$ \\
\hline Fertilization options & $\begin{array}{l}3 \text { fertilization options: } \\
\text { 1. basic scheme: } 100 \% \text { (see above) } \\
\text { 2. increased scheme: } 125 \% \\
\text { 3. reduced scheme: } 75 \%\end{array}$ \\
\hline
\end{tabular}

$P$ - average un-corrected precipitation, $T$ - average daily temperature, sbe - sugar beet, wra - winter rape, wb - winter barley, sb - spring barley, wr - winter rye, sm - silage maize, ww - winter wheat, pot - potatoes, ${ }^{*} 1$ - cover crop wra preceding. 

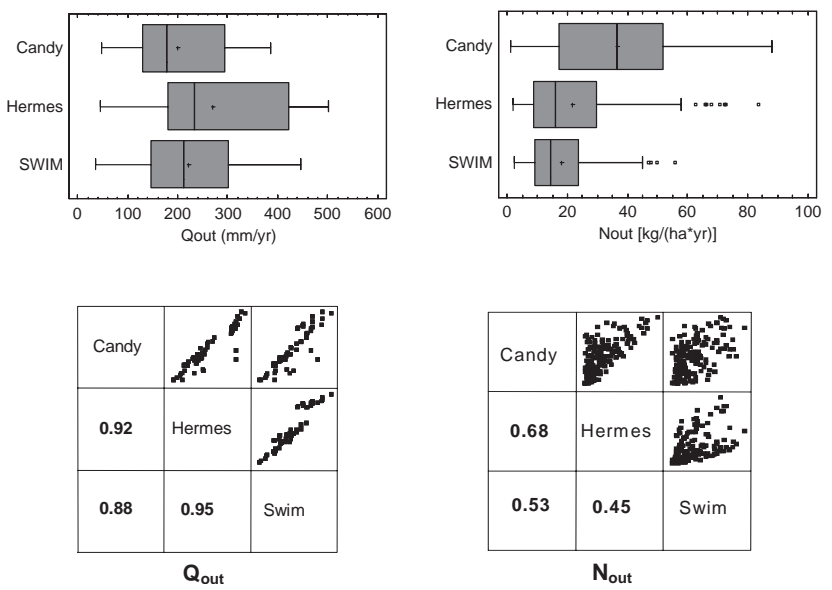

Fig. 4. Box-Whisker-Plots and Correlation-Scatterplot-Matrices for simulated percolation (Q $\left.\mathrm{Qut}_{\text {out }}\right)$ and simulated N-leaching $\left(\mathrm{N}_{\text {out }}\right)$; 162 simulation variants; boxes: interquartil range (IQR), whiskers: 1.5 IQR, median: vertical line, mean: + .

\subsection{Model comparison}

A relative model comparison for the variables water percolation and nitrogen leaching based on the long term annual averages for the 162 simulation variants is carried out here. This analysis is focusing on model comparison and not on the sensitivity of models regarding different factors.

Already the comparison of the empirical distributions of percolation and nitrogen - leaching $\left(\mathrm{NO}_{3}-\mathrm{N}\right)$ between the three models shows considerable differences (Fig. 4, top row). In particular HERMES simulates higher water percolation and CANDY simulates higher N-leaching each than the other two models. However, a correlation analysis reveals that simulated water percolation is much more similar between the three models than simulated nitrogen leaching (Fig. 4, bottom row).

Only the variable nitrogen leaching is further analysed here. Covering the Elbe basin with a raster, all cells are classified according to the factors climate and soil quality with the latter providing the management scheme. Then the simulation results regarding nitrogen leaching are associated to each classified cell. Figure 5 shows the spatial distributions of nitrogen leaching for the increased fertilization variant $(125 \%)$ in the Elbe River Basin. It can be seen, that spatial patterns are simulated quite differently by the three models. This confirms the significant uncertainty in the modelling of $\mathrm{N}$-leaching. It leaves the serious problem which model is to be preferred for decision support.
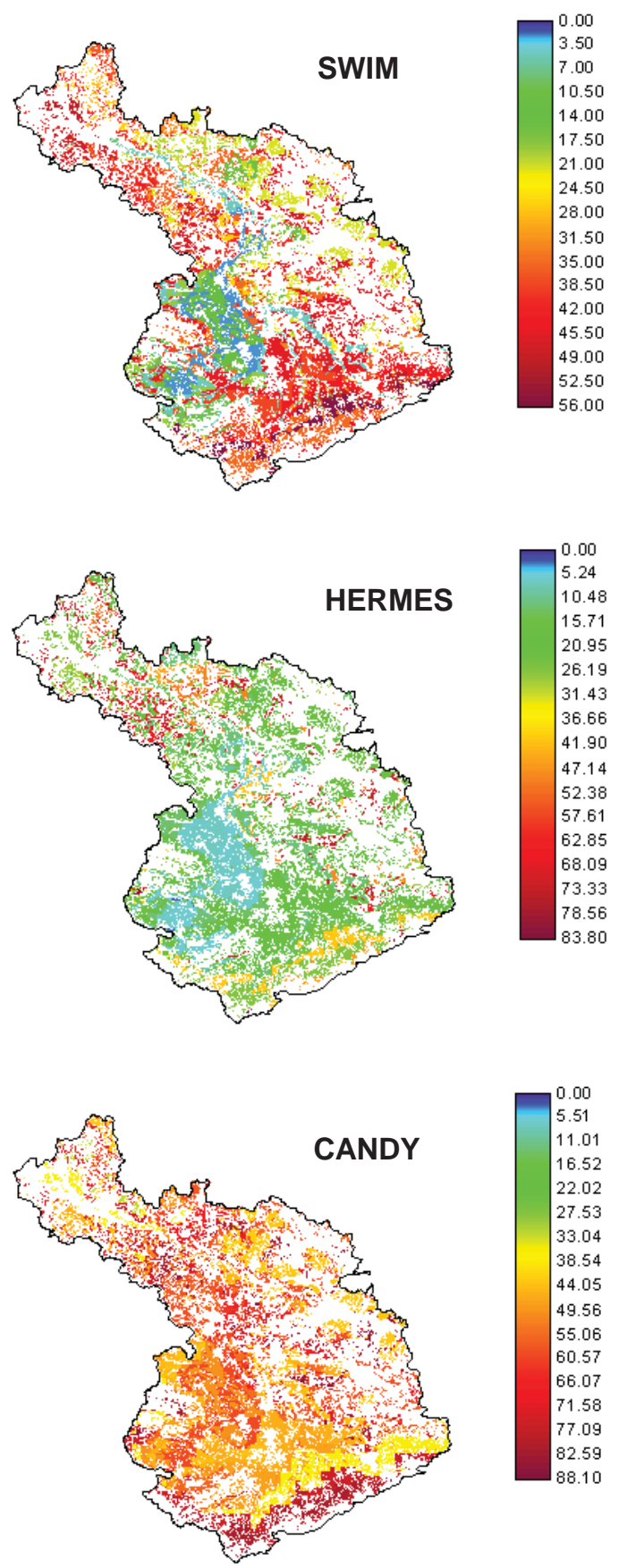

Fig. 5. Spatial distribution of simulated long term average $\mathrm{N}$-leaching in $\mathrm{kg} /\left(\mathrm{ha}^{*} \mathrm{a}\right)(1961-1990)$ for increased fertilization $(125 \%)$ on arable land in the Elbe river basin.

\subsection{Integration of model results}

One possibility to provide decision support is to try to integrate the results of the three models with a generalisation focussing on the prediction of critical regions i.e. "hot spots" for diffuse pollution. For that task fuzzy-set theory is applied here (see e.g. Bárdossy and Duckstein, 1995). 

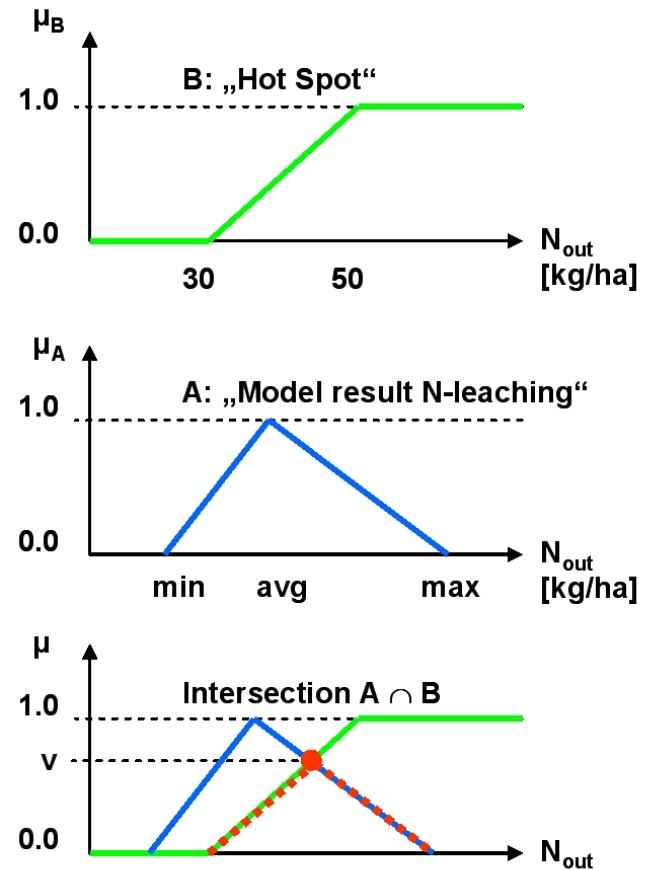

[kg/ha]

Fig. 6. Definition of nitrogen leaching hot spots for the Elbe River Basin; top panel: fuzzy number B = "hot spot"; middle panel: fuzzy number A = "model results"; bottom panel: fuzzy number that "model result" belongs to "hot spot".

First, a fuzzy number has to be defined which describes the "hot spots" for critical nitrogen leaching. A semi-finite triangular fuzzy number $B=\left(y_{1}, y_{2}, \infty\right)_{T}$ is selected here, with exemplarily chosen values of $y_{1}=30$ and $y_{2}=50$ (see Fig. 6 , top). That means, locations with nitrogen leaching above $50 \mathrm{kgN} /$ (ha yr) belong with certainty to the fuzzy set hot spot $\left(\mu_{B}(x)=1\right)$, locations with values below $30 \mathrm{kgN} /($ ha yr) are not critical $\left(\mu_{B}(x)=0\right)$ and locations with $\mathrm{N}$-leaching in between have a membership value between 0 and 1 . Second, the simulation results from the three models have to be integrated, which can be done by expressing them as a fuzzy number. Triangular fuzzy numbers $A_{j}=\left(x_{j 1}, x_{j 2}\right.$, $\left.x_{j 3}\right)_{T}$ are defined, with $x_{j 1}=$ minimum, $x_{j 2}=$ average and $x_{j 3}=$ maximum of the results from the three models SWIM, CANDY and HERMES for each variant $j=1, \ldots, 162$ (see Fig. 6, middle). Finally, the degree of fulfilment, that fuzzy set $\mathrm{A}_{j}$ (simulation result) belongs to the fuzzy set $\mathrm{B}$ (hot spot) can be calculated by the maximum membership of the intersection of A and B (see Fig. 6, bottom). Figure 7 shows the resulting map of hot spots for nitrogen leaching from agricultural land in the Elbe River basin. The degree of fulfilment $v$ (A is B) has further been classified into four groups. According to that classification, larger regions which are very likely to be hot spots can be found in the southern mountainous regions of the Elbe Basin and several more locally organized spots in the flatland regions in the northern part of the basin.

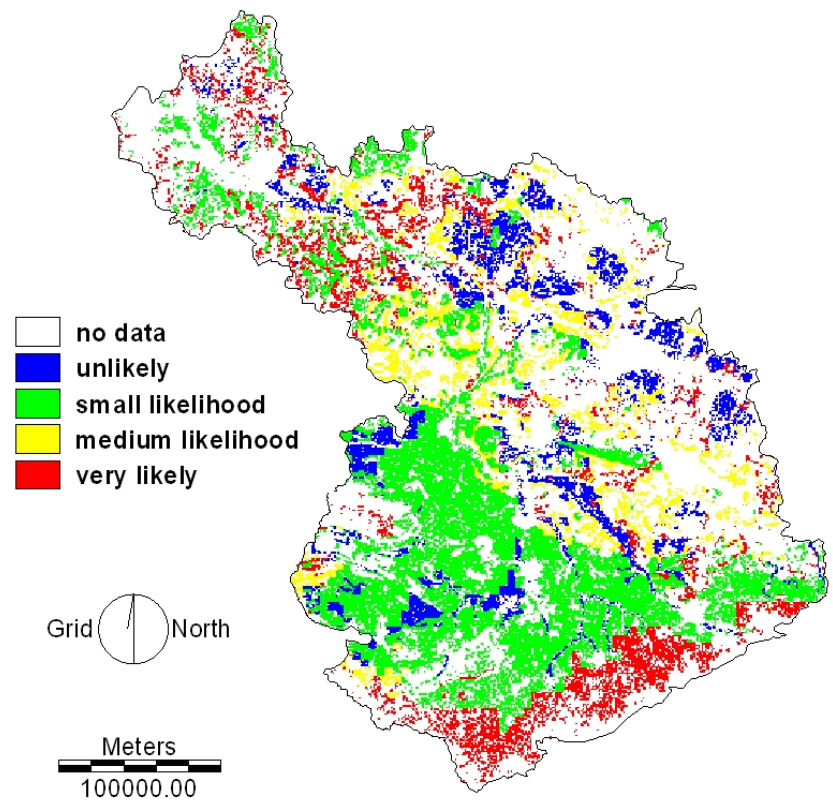

Fig. 7. Hot spots for nitrogen leaching in the Elbe River Basin (unlikely: $v<0.4$; small likelihood: $0.4 \leq v<0.7$; medium likelihood: $0.7 \leq v<0.9$; very likely: $v \geq 0.9$ ).

\section{The metamodel approach}

In Sect. 3, the uncertainty of nitrogen leaching prognosis has been shown and a simple approach for dealing with this uncertainty integrating results from different models has been demonstrated. For practical decision support this approach which includes running of three complex eco-hydrological models is much to demanding. This is especially true if several more target variables are requested and from time to time new scenarios need to be investigated. In this section an alternative concept based on metamodelling is briefly presented.

A metamodel is a substitute for a complex simulation model consisting of simplified, but often nonlinear and dynamic relationships. Metamodels can be trained using results from simulation experiments with available process models, expert knowledge and observations if available. This allows the quantitative integration and regionalization of different specific information and can eventually serve as a "dynamic memory" of expert knowledge.

A general scheme of a metamodel is shown in Fig. 8. There are two different streams of input information required: (a) results from simulation experiments with process models, and (b) physical basin properties, climate data and management options. The first set of information is initially used to identify the metamodel functions, and irregularly for their updating. The second set of information involves all necessary input data to run the model for scenario analysis independently from the process-based models. 


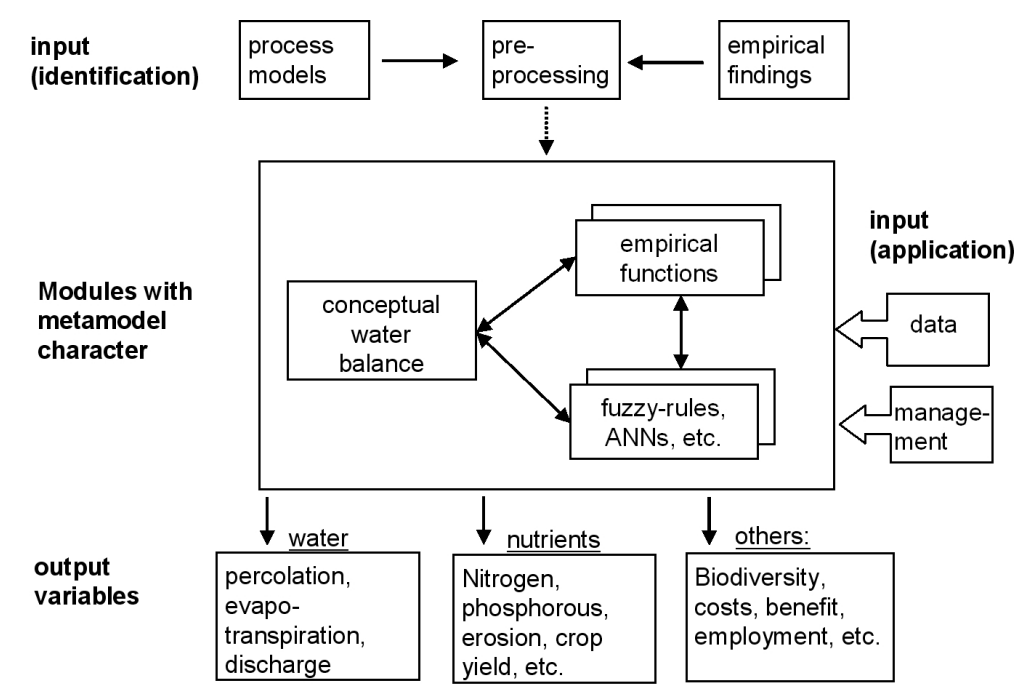

Fig. 8. Conceptual scheme of a metamodel framework.

The metamodel itself can be realized as a hybrid system consisting of different modules for the description of the various target variables. A fuzzy-rule approach might be applied for variables which express high temporal dynamics and a strong nonlinear behaviour (e.g. nitrogen and phosphorous). The application of empirical functions like regressions may be sufficient for the description of parameters with smaller temporal variability and more linear behaviour (e.g. crop yield). However, the water balance components, which serve as drivers for most of the other indicators, are usually directly simulated using a conceptual hydrological model (see Sect. 2).

The modules of the metamodel can be operated at different time steps, e.g. daily steps for the water balance and monthly steps for the nitrate loss module, with the main focus on a good reproduction of the long term behaviour. Those longer time steps allow fast and data parsimonious computations, but usually imply an increase in nonlinearity. The spatial discretisation depends on the original data availability and the specific target variable simulated. Considering the availability of climate and physiographic data for meso- and macroscale applications, the finest length scale which can be resolved for the target variables will be in the range between $100 \mathrm{~m}$ and $5 \mathrm{~km}$. The metamodel approach is intended to provide tools capable of being included into decision support systems (DSS) or eventually becoming a DSS itself. The advantages of the metamodel approach compared to complex process models are the reduced data requirements, less demanding modelling effort and a high integrative potential. The disadvantage is a loss of accuracy and detail, especially related to the decoupling of the modules where the feedbacks can no longer be fully considered.

\section{Conclusions}

In the conclusions the questions posed in Sect. 1 will be tried to answer with respect to the examples discussed in the text.

1. Concerning easy handling for application of hydrological models within a decision support system only the simplest model HEC-HMS can be recommended here. Regarding sensitivity to land use change WaSIM-ETH might be applicable while for a potential sensitivity to agricultural management only the SWAT model is suitable. If hydrological models are needed as part of decision support systems further developments should consider both easy handling and the sensitivity to agricultural management at least regarding crop dynamics.

2. The comparison of simulated water and nutrient fluxes from the models SWIM, CANDY and HERMES has shown that the results are much more different and uncertain for nitrogen leaching than for water percolation. The confidence in those simulation results should be increased by using local measurements e.g. from lysimeters for better parameterization of the models. Integration and generalisation of results from model ensembles is demanding but may lead to more reliable information e.g. about hot spots for decision support.

3. For practical decision support involving many target variables and a regular updating for scenario analyses a hybrid metamodel approach is recommended, which comprises a hydrologic model, empirical relationships for the less dynamic processes and makes use of simulation results from complex eco-hydrologic models through second-order modelling at a generalized level. 
Acknowledgements. The author thanks the organisers of the workshop "Großskalige Modellierung in der Hydrologie" for the invitation and the excellent organisation and the two anonymous reviewers for their helpful comments.

Edited by: A. Wahren, F. Tavares Wahren, and K.-H. Feger Reviewed by: two anonymous referees

\section{References}

Arnold, J. G. and Fohrer, N.: SWAT2000: current capabilities and research opportunities in applied watershed modelling, Hydrol. Process., 19, 563-572, 2005.

Bárdossy, A. and Duckstein, L.: Fuzzy Rule-Based Modelling with Applications to Geophysical, Biological and Engineering Systems, CRC Press, Boca Raton, Florida, 232 pp., 1995.

Berlekamp, J., Lautenbach, S., Graf, N., Reimer, S., and Matthies, M.: Integration of MONERIS and GREAT-ER in the decision support system for the German Elbe river basin, Environ. Modell. Softw., 22, 239-247, 2007.

Fleming, M. and Neary, V.: Continuous Hydrologic Modeling Study with the Hydrologic Modeling System, J. Hydrol. Eng., 9, 175-183, 2004.

Franko, U., Oelschlägel, B., and Schenk, S.: Simulation of temperature-, water- and nitrogen dynamics using the model CANDY., Ecol. Model., 81, 213-222, 1995.

Haberlandt, U., Krysanova, V., Klöcking, B., Becker, A., and Bárdossy, A.: Development of a metamodel for large-scale assessment of water and nutrient fluxes - first components and initial tests for the Elbe River Basin, IAHS Publication, 268, 263269, 2001.

Haberlandt, U., Krysanova, V., Franko, U., Kersebaum, C., and Beblik, A.: Modelling nitrogen leaching from agricultural soils uncertainty assessment, upscaling and integration of model results, 3rd International Conference on Water Resources and Environmental Research, Dresden, 397-401, 2002.
Haberlandt, U., Buchwald, I., van der Heiden, S., and Verworn, A.: Requirements for hydrological models to be used as part of decision support systems in integrated water resources management, in: Int. Symposium on the Role of Hydrology in Water Resources Management, Capri, Italy, IAHS Publications, 327, 29-35, 2009.

Hartwich, R., Behrens, J., Eckelmann, W., Haase, G., Richter, A., Roeschmann, G., and Schmidt, R.: Bodenübersichtskarte der Bundesrepublik Deutschland 1:1 000000 (BÜK1000), Karte mit Erläuterungen, Textlegende und Leitprofilen, Bundesanstalt für Geowissenschaften und Rohstoffe, Hannover, 1995 (in German).

Johnes, P. J.: Evaluation and management of the impact of land use change on the nitrogen and phosphorus load delivered to surface waters: the export coefficient modelling approach, J. Hydrol., 183, 323-349, 1996.

Kersebaum, K. C.: Application of a simple management model to simulate water and nitrogen dynamics, Ecol. Model., 81, 145$156,1995$.

Krysanova, V., Müller-Wohlfeil, D.-I., and Becker, A.: Development and test of a spatially distributed hydrological/water quality model for mesoscale watersheds, Ecol. Model., 106, 261-289, 1998.

Kunkel, R. and Wendland, F.: The GROWA98 model for water balance analysis in large river basins - the river Elbe case study, J. Hydrol., 259, 152-162, 2002.

Quinn, P. F., Hewett, C. J. M., and Dayawansa, N. D. K.: TOPCATNP: a minimum information requirement model for simulation of flow and nutrient transport from agricultural systems, Hydrol. Process., 22, 2565-2580, 2008.

Scheffer, F. and Schachtschabel, P.: Lehrbuch der Bodenkunde, 11 edn., Enke, Stuttgart, 1984 (in German).

Schulla, J.: Hydrologische Modellierung von Flussgebieten zur Abschätzung der Folgen von Klimaänderungen., Züricher Geographische Schriften, Zürich, 1997 (in German).

Shrestha, R. R., Bardossy, A., and Rode, M.: A hybrid deterministic-fuzzy rule based model for catchment scale nitrate dynamics, J. Hydrol., 342, 143-156, 2007. 